\title{
PRODUCED LOW COST AND SUFFICIENT QUALITY DYED YARNS FROM BLENDING SOME EGYPTIAN COTTON VARIETIES AND GRADESWITH COMBED COTTON WASTE Arafa, Abeer S. and S. Mansor Agricultural Research Center, Cotton Research Institute, Giza Egypt.
}

\begin{abstract}
This investigation provides a new method for produced dyed yarns of low cost and sufficient quality to be used for garment manufacture using some Egyptian cotton varities of different grades and consequently different Maturity percentages in combination with combed cotton waste in different ratios in open end (O.E) spininig process. In this study we tried to find facilities looking to upgrade the disposal comber noils into medium dyed yarns. We succeeded in choosing Giza 88 cultivar combing noils to blend with both Giza 80 and Giza 90 as a long Upper Egypt cultivars which described as coarse and short as compared with the other Egyptian cultivars and their creamy color similar to the combed waste. Measurements of fiber maturity percentage, Fiber and yarn properties, dye ability, and color difference properties of the produced blends were studied. The results obtained revealed that the best values for all the fiber and yarn characters considered that open end was the favorable system for this investigation. The results show that the micronair reading, hair weight (H.W), upper half mean, uniformity index, color strength (K/S) and color difference showed decrease as the ratio of the cotton varieties decreased.
\end{abstract}

\section{INTRODUCTION}

Egyptian cotton is known for its superiority and high quality. Egypt produces $50 \%$ of the world's production of long and extra long staple cotton. However, Egypt have many problems in its cotton production due to control of exports of Egyptian cotton lint from the early sixties to the late eighties. Egyptian mills depended on the Egyptian cotton as its source of raw material and Egyptian farmers depended on the government-run textile industry as its client.

The control of environmental pollution is very essential to establish healthy working atmosphere in and around textile industries. Textile wastes could be also utilize for manufacturing of certain products.

The demand for cotton fiber has increased in the recent years. The cotton mills all over the world needed to find ways to reduce the disposal cotton wastes and upgrade it as a saleable products or additive values. This considered as an indicator to reduce the cost of the produced garments. The properties of the Egyptian cotton varieties are the highest among the other cottons around the world, especially extra- long and extra fine cotton, so, the price of these varieties are very expensive and lead to high price of produced garments.

Ashour et al, (1991) found that the coarse and medium yarns produced from high quality Egyptian cottons may not be economical due to the high cost of the raw material. They added that the combing wastes were longer, uniform, strong and fine than the other wastes. 
Ruge (1993) cleared that fibers of widely varying lengths including extremely short fiber could be processed on rotor spinning machines to produce yarns of outstanding uniformity.

Mohammed and El-sayed (2002) found that the short fiber index, micronaire reading and strength indicated the greatest influence upon open end yarn strength. They also added that the open end rotor spinning offers the opportunity for variable spinning of cotton comber noils wastes and low quality cottons prepared in recycling process for end uses with adequate yarn quality.

Abd El-Razik and El-Khatib (2003) reported that the upper Egypt cottons were suitable for open-end spinning specially Giza 91, and Giza 90 that exceeded the other ones grown in upper Egypt in yarn quality under open- end system.

Mabrouk and Nour (2005) indicated that the fiber strength, yarn lea product, yarn tenacity, fiber elongation parentage, fiber length parameters and fiber maturity percentage decreased as the waste percentage increased in the blend. On the other hand micronaire values, hair weight, single yarn strength, yarn elongation, yarn unevenness, C.V\%, thick places and neps increased as the waste percentage increased in the blend. They also added that it's possible to spin and blend the wastes with different percentages of Giza 90 cotton variety by open- end rotor spun coarse counts.

Hassan (2006) emphasized that blending raw cotton at $90 \%$ with $10 \%$ combing wastes maintained the studied properties $(2.5 \%$ fiber length, the uniformity ratio, fiber strength, micronaire value and maturity ratio) from deterioration as result of blending process. These values didn't significantly differ in comparison with $100 \%$ cotton. Also, it aimed the goal through 10 's yarn count and 4.0 twist multiplier and resulted yarns contained fewer numbers of thin, thick places and low C.V\%.

.,Azza et al., (2005) studied the effect of dyeing efficiency of some Egyptian cotton fibers of different maturity levels. Six cotton cultivars represent samples of fibers of four grades (maturity ratios) as FG, G, GFG, and GF were dyed with direct and reactive dyes before and after mercerization treatment. They also revealed that differential response among different varieties to dyeing with the dyestuffs utilized in this study. The color strength was the highest when the reactive dyestuff was applied, followed in descending order by direct dye.

Foil and Boger (2000) described a process for producing dyed spun cotton yarns having a reduced number of irregularities and increased luster. The process involves dyeing at least a portion of the cotton fibers which are to form the yarn, then combing the dyed fibers subsequent to the dyeing process. The dyed and combed fibers are then optionally blended with fibers having a visually distinct appearance, and spun into a yarn using conventional spinning methods. The resulting yarns having a dramatically reduced number of thick and thin places and improved yarn properties including improved luster and hand. Furthermore, when the thus-dyed fibers are blended with differently-colored fibers prior to the combing operation, the resultant yarns match the visual colors of like-colored yarns produced by conventional processes, while the color is more intimately blended and the 
yarns have a markedly increased uniformity, luster and tenacity. As a result, fabrics produced from the yarns have a superior appearance with respect to color blend and luster, and the number of neps and irregularities are dramatically reduced with respect to those of conventionally-produced fabrics.

El Mogahzy (1996) indicated that a complete characterization of a cotton mix can only be achieved through description of both the fiber profile (average fiber properties and variability), and the cost profile of the mix. Determining the cost profile is critical for making proper purchasing decisions of cotton fibers, and for minimizing the cost of raw material with respect to the overall manufacturing cost of yarn. The author developed an integrated program for determining a technological premium/discount scale reflecting the cost of fibers in relation to a particular spinning system and yarn count. The detail of this program is outside the scope of this paper, but the reader is encouraged to refer to the reference indicated.

Krause and Soliman (1971) mentioned that open-end yarns have the higher color strength value than the rotary spinning yarns. This finding due to the poor fiber parallelization in addition, the core of open-end yarn contains fibers deposits uniformity, so, it has poor orientation of hooked fibers results in a large diameters which facilities the increase of dye uptake.

The present investigation provides a new method for manufacturing dyed yarns using some Egyptian cotton varities in combination with recycled cotton waste in different ratios with the open end spinning processe to produce dyed yarns of low cost and sufficient quality to be used for garment manufacture.

\section{MATERIALS AND METHODS}

Materials:

This study was conducted at Cotton Research Institute, Agricultural Research Center to investigate the influence of blending with either Giga 90 or Giza 80 cotton cultivars and combing waste of Giza 88 (extra-long), at three different grades. The following blending treatments were studied as follows:

$100 \%$ of Giza 80, and Giza 90 in the order of Good / fully good (GFG), Good (G), and Good fair (GF) grades respectively.

1- Blends of Giza 80 with the combed cotton waste of Giza 88 in the order of $75: 25,50: 50$, and $25: 75 \%$ for GFG, G, and GF respectively.

2- Blends of Giza 90 with the combed cotton waste of Giza 88 in the order of $75: 25,50: 50$, and $25: 75 \%$ for GFG, G, and GF respectively.

3- $\quad 100 \%$ of Giza 88 combed waste.

All chemicals used were of analytical grade using doubly distilled water (18.5 M $\left.\Omega . \mathrm{cm}^{-1}\right)$. $\mathrm{NaOH}$ was analytical grade (Koch-Light Co.). Hydrogen peroxide (30\%. LR grade) obtained from Aldrich. Sodium carbonate (LR grade), sodium silicate $\left(136^{\circ} \mathrm{Tw}, 27 \% \mathrm{SiO}_{2}\right)$, the wetting agent was the commercially Mercerol supplied by Merck. The hydrogen peroxide bleach liquor for each bleaching process was analyzed by titration with potassium permanganate. 


\section{Methods: \\ Manufacture of the yarns}

The blending was carried out according to the standard method designed by ASTM [D: 144-25]. Open-end rotor spinning was used to perform the spinning process to produce the different yarns in a count of 40's and 4.0 twist multipliers.

\section{Scouring, and bleaching treatments:}

Scouring of the samples (fiber and yarns) were performed by the pad-steam technique by padding the samples with $10 \%$ sodium hydroxide containing $1.5-2 \%$ of an anionic detergent in a two-bowel padding mangle adjusting the squeeze pressure to enable wet pick-up of $100 \%$. The samples were steamed in a laboratory steamer at $100^{\circ} \mathrm{C}$ for 10 minutes. The scoured samples were washed in water, neutralized with dilute acetic acid, further washed with water and finally dried in air.

Unbleached samples were immersed in an alkaline bleach liquor $\left(180 \mathrm{ml}\right.$ deionized water) containing sodium carbonate $\left(0.2 \mathrm{gl}^{-1}\right)$, sodium hydroxide $\left(1.5 \mathrm{gl}^{-1}\right)$, sodium silicate $\left(0.4 \mathrm{gl}^{-1}\right)$, magnesium sulphate $\left(0.2 \mathrm{gl}^{-1}\right)$, wetting agent $\left(0.5 \mathrm{gl}^{-1}\right)$ and Hydrogen peroxide $\left(10 \mathrm{ml}^{-1}\right)$ was added to the bleach liquor and bleaching was done. The samples were removed from the liquor and neutralized with aqueous solution containing $0.1 \%$ acetic acid, followed by a through hot water $\left(80-85^{\circ} \mathrm{C}\right)$ washing to ensure removal of residual chemicals. Samples were dried in an oven at $100^{\circ} \mathrm{C}$ for 60 minutes.

\section{Dyeing process:}

The samples were dyed in solutions of reactive dye Procion Crimson CX-B. The dyeing was carried out at a liquor ratio of $1: 20$, in a sealed stainless steel dye bath. The temperature and duration of dyeing were $80^{\circ} \mathrm{C}$ and $45 \mathrm{~min}$. respectively. After dyeing, the dyed samples were taken out and rinsed thoroughly in tap water, and dried freely in open air, then subjected to soaping off in a boiled solution containing $5 \mathrm{~g} / \mathrm{l}$ non-ionic surfactant for 15 min. at the liquor ratio of 1: 50. The soaped-off dyed samples were then rinsed in tap water and dried freely in open air.

\section{Tests:}

Measurements of fiber maturity percentage

Maturity percentage (PM \%), was determined by using sodium hydroxide method according to Lord (1961).

\section{Fiber and yarn properties:}

1) Upper half mean of fiber mean (UHM) and Uniformity index (UI) were determined by Fibrograph Model 530 according to [ASTM d: 1447-67].

2) Fiber strength ( $g /$ tex) was determined by Stelometer tester according to [ASTM D: 1445-67].

3) Fiber fineness (millitex) was determined using Micromate instrument according to [ASTM D: 3818-1986].

4) Micronaire reading was estimated using Micronaire 275 instrument according to [ASTM D: 1448-2006].

Yarn properties 
1) Lea product was determined by testing skein strength on the Good Brand [Lea tester] instrument according to [ASTM D: 157867].

2) Single yarn strength and elongation\% were measured on the Zwick 1511 automatic tensile tester according to [ASTM D: 225684].

3) Yarn evenness (C.V \%) was estimated using Uster3 instrument Measurements of dye ability: according to [ASTM D: 1425-84].

The color strength $(\mathrm{K} / \mathrm{S})$ of the samples was determined according to CIE system using Perkin Elmer Spectrophotometer, Model Lambda 35 equipped with integrated sphere according to Kubelka-Munk equation:

$$
K / S=\left[(1-R)^{2 / 2 R}\right]
$$

Where $\mathrm{K} / \mathrm{S}$ is the color coefficient and $\mathrm{R}$ represent the reflectance The color difference $(\Delta \mathrm{E})$ of the dyed yarns that can be calculated according to the following equation

$$
\Delta \mathrm{E}=\left[\Delta \mathrm{L}^{2}+\Delta \mathrm{a}^{2}+\Delta \mathrm{b}^{2}\right]^{1 / 2}
$$

Where L (light- dark), a (red- green), and b (yellow-blue) represents the viewing angle and other conditions for the dyed yarns.

The obtained results subjected to statistical analises according to Sendcor and Cochran (1982). The experiments were in randomized complete blocks design with four replicates. Means were compared using the significant differences (LSD) at $5 \%$ level of probability. The aforementioned tests were conducted in standards condition of $(65 \pm 5 \%)$ relative humidity and $\left(21 \pm 2^{\circ} \mathrm{C}\right)$ temperature.

\section{RESULTS AND DISCUSSIONS}

The different maturity values of the previous cultivars were obtained from "Cultivar Maintenance Department, Cotton Res. Inst." In the growing season crops of 2006. Maturity percentage (PM \%) values of the previous cultivars under study are shown in Table 1.

Table 1: Fiber maturity percentage (PM \%) values of Giza 80, and Giza 90 of different grades

\begin{tabular}{|c|c|c|}
\hline \multirow{2}{*}{ Grades } & Giza 80 & Giza 90 \\
\cline { 2 - 3 } & \multicolumn{2}{|c|}{ PM \% } \\
\hline Good fully good (GFG) & 88.7 & 86.1 \\
\hline Good (G) & 75.3 & 73.2 \\
\hline Good fair (GF) & 67.8 & 65.9 \\
\hline
\end{tabular}

Data pertaining to fiber properties are illustrated in Table 2. The results indicated that most interactions did not reach the significant level, so, focused on the main factors. Data indicated that Micronair reading, and consequently H.W decreased as raw cotton \% and PM \% decreased in the 
cotton blend. However, fiber strength showed slight decrement. This finding due to the noils extracted from $G 88$ cultivar which has strong fibers also, only the longest and consequently the strongest fibers of the combed waste are clamped in the jaws. Thus, it could be arranged in descending order according to the blend ratio as follows: $100 \%$ raw cotton (r.c), $75 \%$ r.c $+25 \%$ combing waste (c.w), $50 \%$ r.c $+50 \%$ c.w and $25 \%$ r.c $+75 \%$ c.w. Therefore, it is worthy to focus on the second and the third blends still having fairy good characters depends on the spinning system and the final product because the reduction percentage in micronaire reading from the second to the fourth blends were $(4.6 \%$ and $9.5 \%)$ respectively as well as $(2.8 \%$ and $9.5 \%$ for the $\mathrm{HW})$. However, the deterioration in the fiber strength $(0.0 \%$ and $3.7 \%)$, as compared with $100 \%$ cotton. Also, it could regarded that the first and the second $\mathrm{Pm} \%$ having fairy good fiber characters. Specially if it is known that at combing we exclude short and immature fibers in addition, G 88 cultivar considered finer than both of $\mathrm{G} 80$ and $\mathrm{G} 90$ cultivars. Thus, as expected decline in the reading of fineness and maturity parameters. This finding due to that micronaire reading is associated with two factors, the first is Perimeter (intrinsic fineness) and the second is the wall thickness (maturity). Perimeter is a genetic factor, so its variation is limited. Thus, maturity was the operating factor under this study. Also, H.W refers to fiber length unit's weight so, the highest in fiber maturity, the highest in H.W. As the fact that during the secondary wall thickness process, sugars converted into cellulose and deposits in a successive layers causing high percentage of maturity more tolerant during mechanical processes and high fiber strength. These results were in agreement with those obtained by Mabrouk and Nour (2005) and Hassan (2006).

Data pertaining to fiber UHM, and UI (4.6\% and 9.5\%) showed that G 80 cultivar exceeded G 90 cultivar in UHM with the percentage $(30.1 \%$ and $29.8 \%$ ). While, the diverse between the cultivars meaning values belonged to $\mathrm{UI}$ did not reach the significant level. According to the effect of blend ratio, there were general trend for the both characters indicating that UHM and UI were enhanced positively as raw cotton \% was increased in the blend, whereas the reduction \% ranged from $(0.3 \%$ to $10.71 \%)$ for UHM and from $(0.3 \%+9.3 \%)$ fro $\mathrm{UI}$ at the second and fourth blends as compared with $100 \%$ cotton blend. Nevertheless, it still spinable especially in open end system. This may be described to that G 88 cultivar is extra long cultivar, therefore, its comber wastes did not cause high deterioration in the previous characters especially if the varities from the long category grown in Upper Egypt. It could be mentioned that the high maturity ratio is usually accompanied with the maximum reading $(30.5 \mathrm{~mm}$ and 86.2$)$ for UHM and UI respectively and vice versa .This finding due to high mature fibers don't breakage easily and bear over loading this preserve the UHM and UI characters. These results were in agreement with the results obtained by Mabrouk and Nour (2005) and Hassan (2006). It could be concluded that even though all the second order interactions did not reach the significant level but G 90 cultivar, $75 \%$ and 50 $\%$ row cotton and the highest and medium $\mathrm{PM} \%$ reading for all the previous characters possessed the best values for fiber Mic, Strength and length. Also, we can added that deterioration due to adding $G 88$ combing noils 
whatever been its quantity did not affect the mechanical processes on open end Spinning system because $\mathrm{G} 88$ cultivar is ranked as extra long cultivar.

Data belonging to yarn properties of the two investigated cultivars under adopted treatments are presented in Table 3 . The results revealed that G 80 cultivar exhibited the highest mean values for all the yarn characters under the investigation. Moreover, as the waste \% increased in the blend or the maturity \% decreased, the inferred results indicates reduction in both of lea product, single yarn strength, elongation $\%$ and c.v \% .As the combed waste ratio for the blend increased from $25 \%$ to $75 \%$ reduction of the yarn strength values increased from $2.4 \%$ to $12.7 \%$, single yarn strength from $6.6 \%$ to $33.6 \%$ and elongation $\%$ from $6.4 \%$ to $23.8 \%$, while the c.v\% decreased from $42.4 \%$ to $10.5 \%$. This may be attributed to that the high percentage of raw cotton, the high value of fiber strength, micronaire reading, length and maturity ratio and lower values of short fiber content and immature fibers which serves the follows: fiber strength transforms practically to the yarn in addition, the longer the fiber, the higher the point of contact also, the finer fiber the higher number in cross section and consequently higher yarn strength. These results are in agreement with those found by Ashour et al., (1991), Mohammed and El-Sayed (2002), Mabrouk and Nour (2005) and Hassan (2006).

Data pertaining to color properties of the produced blends were illustrated in Table 4. It was found that dyeing increases fiber damage. The quality of yarn depends considerably on the blending stage, as well as the spinning systems.

The higher number of drawing stages when blending fibers in the draw frame results in better mechanical properties, but greater hairiness for the yarn. The presence of dyed yarns leads to a considerable decrease in the mechanical properties of rotor spun yarns,. Data indicated that K/S readings, and consequently $\mathrm{R} \%$ decreased as raw cotton \% and $\mathrm{PM} \%$ decreased in the cotton blend. Thus, it could be arranged in descending order according to the blend ratio as follows: $100 \%$ raw cotton (r.c), $75 \%$ r.c $+25 \%$ combing waste (c.w), $50 \%$ r.c $+50 \%$ c.w and $25 \%$ r.c $+75 \%$ c.w. Therefore, it is worthy to focus on that the second and the third Blends still having fairy good characters depends on the spinning system and the final product because the reduction percentage in micronaire reading from the second to the fourth blends.

Data pertaining to $\mathrm{K} / \mathrm{S}$ and $\Delta \mathrm{E}$ showed that G80 cultivar exceeded G90 cultivar as follows: $(27.7,85$ and $27.4,79.3)$. this is due to decrease in maturity\%, and micronaire reading parallel with decrease in lint grades and cellulose $\%$, so, the dyeing response changed from grade to other. 
Arafa, Abeer S. and S. Mansor 
J. Agric. Sci. Mansoura Univ., 33 (12), December, 2008

3

8501 
Arafa, Abeer S. and S. Mansor 


\section{CONCLUSION}

We succeeded in choosing G88 cultivars combing noils to blend with both of G80 and G90 cultivars first because both of G80,G90 and G88 were considered as a creamy cultivars and the noils is still fairy strong and long and has lower fineness .specially we deal with long upper Egypt cultivars which described as coarse weak and short cultivars as compared with the other Egyptian cultivars. G90 cultivar, $75 \%$ or $50 \%$ row cotton of the highest and medium $\mathrm{PM} \%$ reading possessed the best values for all the fiber and yarn characters also; we can added that deterioration due to adding G88 combing noils whatever been its quantity did not affect the mechanical processes on open End Spinning system .there results are very important to the textile industry for both spinning and dyeing as well

\section{REFERENCES}

Abd El-Razek, F.B and El khatib, F.K; (2003), J. Appl. Scin; 18 (4)

Azza A. M., Amal S, and Salah M. s; (2005), Agric. Res, J. 83 (1)

American stander for testing materials (ASTM), D144,,(1925).; D1447, D1445 and D1578 (1967).; D1425 and D2256(1984).; D3818 (1986).; D1448(2006). USA.

Ashour, A.Y.,Abd El-fattah , M.T. Abd El-Mohsen , M.A. and Esmai, A.M; (1991), Egypt cott. .Gaz. 97:10-21.

El Mogahzy, Y; (1996), Beltwide cotton conference, San Antonio, TexasJan. 3-6 , pp. 1906-1920

Foil Jr., and Martin Boger; (2002), United States Patent, 6354067.

Hassan, A. A ;( 2006), Low priced medium and coarse yarn with acceptable quality Using Rotor Spinning System. Ph.D Thesis. Faculty of Agriculture Al-Azhar University. Egypt.

Krause, H.W. and Soliman H. A; (1971), Tex. Res. J.,41:101-108.

Lord, E; (1961). Manuel of cotton spinning .Part I: the characteristics of row cotton. Vol11, the textile inst, Manchester.

Mabrouk, K.I and Nour, O.D; (2005), Agric. Res, J. 83 (3)

Mohammed,A.M. and El-sayedM.A.A;(2002).Agric.Res,J.80(4):1709-1718.

Ruger, E.H; (1993), Customer Day For the Egyptian Textile Industry. In Alexandria on 19 June.

Snedecor, G.W. and Cochran, W.G; (1982). Statistical Method, Lowa Stat. Univ. presses. 
إنتاج غزل مصبوغ بتكلفة منخفضة وجودة مقبولة من خلط بعض أصناف ورتب القطن المصري بعول معرم ادم التمشيط

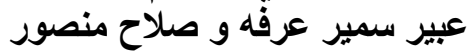
معهز بحوث القطن- مركز البحوث منصو الزراعيةــ الجيزة- مصر

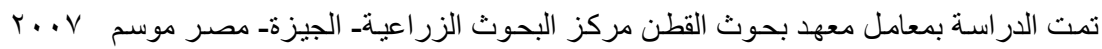

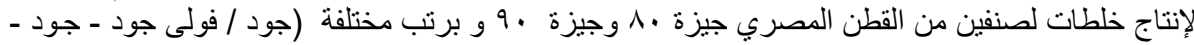

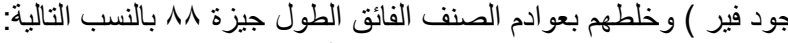

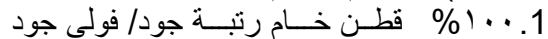

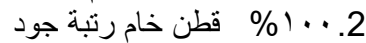

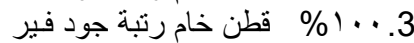

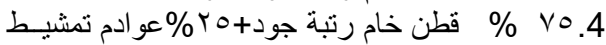

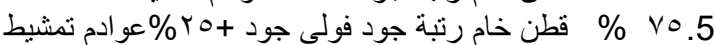

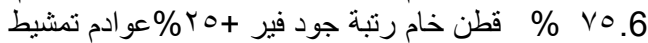
\% 0.7

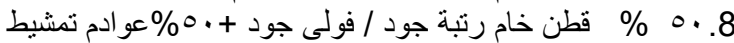

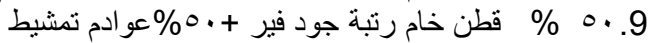

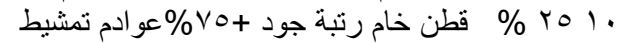

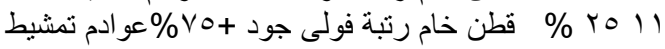

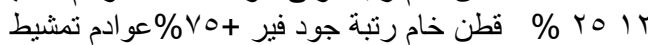

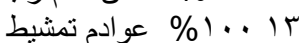

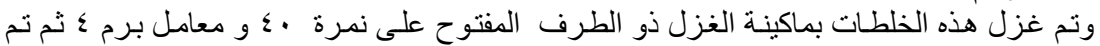

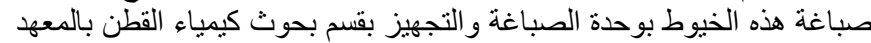

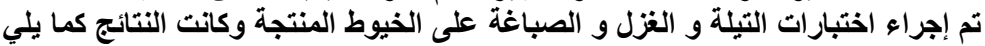

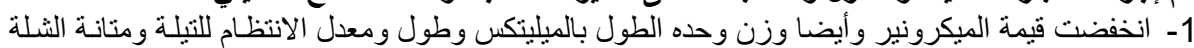
ومتانة واسنطالة الخيط المفرد اليكرو

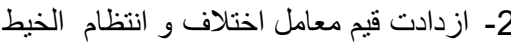

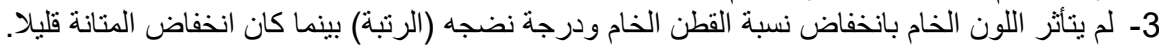

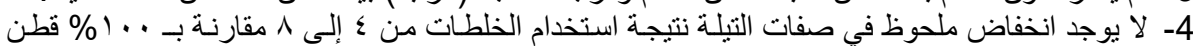

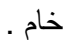

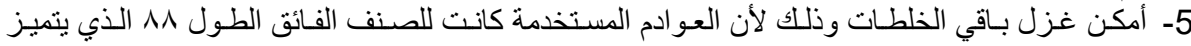

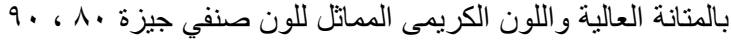

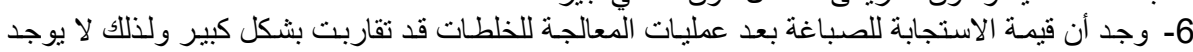

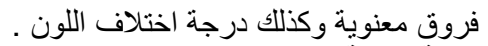

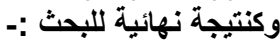

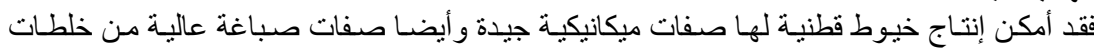

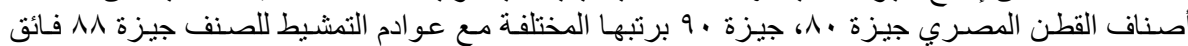

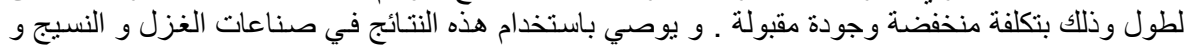


Table (2) : Fiber properties as affected by cultivars ,blends ratio and maturity percentage

\begin{tabular}{|c|c|c|c|c|c|c|c|c|c|c|c|c|c|c|c|c|c|c|c|c|c|}
\hline \multirow{2}{*}{\multicolumn{2}{|c|}{$\begin{array}{l}\text { Characters } \\
\text { maturity } \%\end{array}$}} & \multirow{3}{*}{ m1 } & \multirow{3}{*}{$\begin{array}{l}\text { mic } \\
\mathrm{m} 2\end{array}$} & \multirow{3}{*}{$\mathrm{m} 3$} & \multirow{3}{*}{ ๕్ } & \multicolumn{3}{|c|}{ HW(millitex) } & \multirow{3}{*}{ हृ } & \multirow{3}{*}{ m1 } & \multicolumn{2}{|c|}{$\begin{array}{c}\text { strength } \\
\text { (gltex) }\end{array}$} & \multirow{3}{*}{ 胥 } & \multicolumn{3}{|c|}{$\mathrm{UHM}(\mathrm{mm})$} & \multirow{3}{*}{$\begin{array}{l}\text { \& } \\
\text { है }\end{array}$} & \multirow{3}{*}{ m1 } & \multirow{3}{*}{\begin{tabular}{|l|} 
Ul\% \\
m2
\end{tabular}} & \multirow{3}{*}{ m3 } & \multirow{3}{*}{ हू } \\
\hline & & & & & & \multirow[t]{2}{*}{ m1 $n$} & \multirow[t]{2}{*}{ m2 } & \multirow[t]{2}{*}{ m3 } & & & \multirow[t]{2}{*}{ m2 } & \multirow[t]{2}{*}{ m3 } & & \multirow[t]{2}{*}{ m1 } & \multirow[t]{2}{*}{ m2 } & \multirow[t]{2}{*}{ m3 } & & & & & \\
\hline cultivar & blends & & & & & & & & & & & & & & & & & & & & \\
\hline & b1 & 4.6 & 4.3 & 4.0 & 4.3 & 185 & 183 & 180 & 183 & 38.9 & 38.1 & 38.1 & 38.4 & 32.2 & 32.1 & 31.9 & 32.1 & 88.3 & \begin{tabular}{|l|}
87.7 \\
\end{tabular} & 87.1 & 87.7 \\
\hline & b2 & 4.3 & 4.1 & 3.8 & 4.1 & 181 & 179 & 175 & 178 & 38.7 & 38.9 & 38.3 & 38.6 & 31.3 & 31.0 & 30.1 & 30.8 & 88.1 & 88.1 & 87.3 & 87.8 \\
\hline G 80 & b3 & 4.0 & 3.9 & 3.7 & 3.9 & 176 & 173 & 165 & 171 & 37.3 & 37.0 & 37.0 & 37.1 & 30.4 & 29.7 & 29.5 & 29.9 & 85.2 & 84.3 & 81.0 & 83.5 \\
\hline & b4 & 3.8 & 3.7 & 3.7 & 3.7 & 155 & 150 & \begin{tabular}{|l|}
143 \\
\end{tabular} & 149 & 37.9 & 37.0 & 36.9 & 37.3 & 29.3 & 28.7 & 28.0 & 28.7 & 83.1 & \begin{tabular}{|l|}
81.1 \\
\end{tabular} & 78.7 & 81.0 \\
\hline & mean & 4.2 & \begin{tabular}{|l|}
4.0 \\
\end{tabular} & 3.8 & 4.0 & 174 & 171 & \begin{tabular}{|l|}
166 \\
\end{tabular} & 170 & 38.2 & 37.8 & 37.6 & \begin{tabular}{|l|}
37.8 \\
\end{tabular} & 30.8 & 30.4 & 29.9 & 30.3 & 86.2 & \begin{tabular}{|l|}
85.3 \\
85.3
\end{tabular} & 83.5 & 85.0 \\
\hline & b1 & 4.5 & 4.1 & 3.8 & 4.1 & 179 & 175 & 173 & 176 & 38.1 & 37.7 & 36.9 & 37.6 & 32.7 & 32.3 & 32.0 & 32.3 & 90.5 & 88.6 & 88.0 & 89.0 \\
\hline & b2 & 4.3 & 4.0 & 3.6 & 4.0 & 174 & 172 & 165 & 170 & 37.6 & 37.4 & 37.1 & 37.4 & 31.7 & 30.5 & 29.9 & 30.7 & 88.7 & 88.2 & 88.0 & 88.3 \\
\hline G 90 & b3 & 4.1 & 3.8 & 3.5 & 3.8 & 160 & 153 & 146 & 153 & 36.7 & 35.8 & 35.8 & 36.1 & 29.8 & 28.7 & 28.2 & 28.9 & 85.2 & 84.2 & 82.0 & 83.8 \\
\hline & b4 & 3.8 & 3.6 & 3.3 & 3.6 & 144 & 140 & 135 & 140 & 36.2 & 35.8 & 35.1 & 35.7 & 27.6 & 27.5 & 27.0 & 27.4 & 80.3 & 80.1 & 77.6 & 79.3 \\
\hline & mean & 4.2 & 3.9 & 3.6 & 3.9 & 164 & 160 & 155 & 160 & 37.2 & 36.7 & 36.2 & 36.7 & 30.5 & 29.8 & 29.3 & 29.8 & 86 & 85.3 & 83.9 & 85.1 \\
\hline & b1 & 4.6 & 4.2 & 3.9 & 4.2 & 182 & 179 & \begin{tabular}{|l|}
177 \\
\end{tabular} & 179 & 38.5 & 37.9 & 37.5 & 38.0 & 32.5 & 30.5 & 30.0 & 31.0 & 89.4 & 88.15 & 87.55 & 88.4 \\
\hline & $b 2$ & 4.3 & 4.1 & 3.7 & 4.0 & 178 & 176 & 170 & 174 & 38.2 & 38.2 & 37.7 & 38.0 & 31.5 & 30.8 & 30.0 & 30.8 & 88.4 & 88.15 & 87.65 & 88.1 \\
\hline blends & b3 & 4.1 & 3.9 & 3.6 & 3.8 & 168 & 163 & 156 & 162 & 37.0 & 36.4 & 36.4 & 36.6 & 30.1 & 29.2 & 28.9 & 29.4 & 85.2 & 84.25 & 81.5 & 83.7 \\
\hline & b4 & 3.8 & 3.7 & 3.5 & 3.7 & 150 & 145 & 139.0 & 145 & 37 & 36 & 36 & 36.5 & 28.5 & 28.1 & 27.5 & 28.0 & 81.7 & 80.6 & 78.15 & 80.2 \\
\hline & mean & 4 & 3.9 & 3.7 & 3.9 & 169 & 166 & 160 & 165 & 38 & 37.2 & 36.9 & 37.3 & 30.6 & 29.6 & 29.1 & 29.8 & 86.2 & 85.3 & 83.7 & 85.1 \\
\hline G88 & & & 3.4 & & & 132 & & & & & 37.5 & & & & 29.1 & & & & 66.9 & & \\
\hline LSD & & Cultivar: & & & 0.004 & & & & 0.22 & & & & 0.05 & & & 0.014 & & & & & N.S \\
\hline & & Blends ratio: & & & 0.002 & & & & 0.27 & & & & 0.027 & & & 0.020 & & & & & 0.32 \\
\hline & & Maturity\%: & & & 0.001 & & & & 0.65 & & & & \begin{tabular}{|l|}
0.65 \\
\end{tabular} & & & 0.018 & & & & & 0.27 \\
\hline & & CxB: & & & 0.006 & & & & 0.74 & & & & 0.74 & & & 0.035 & & & & & N.S \\
\hline & & CxM: & & & 0.011 & & & & 0.77 & & & & \begin{tabular}{|l|}
0.77 \\
\end{tabular} & & & 0.042 & & & & & N.S \\
\hline & & BxM: & & & 0.018 & & & & \begin{tabular}{|l|}
0.8 \\
\end{tabular} & & & & N.S & & & N.S & & & & & N.S \\
\hline & & CxBxM: & & & N.S & & & & N.S & & & & N.S & & & N.S & & & & & N.S \\
\hline
\end{tabular}


Table (3): Impact of cotton cultivars blend ratio and fiber percentage on Lea product single yarn strength elongation

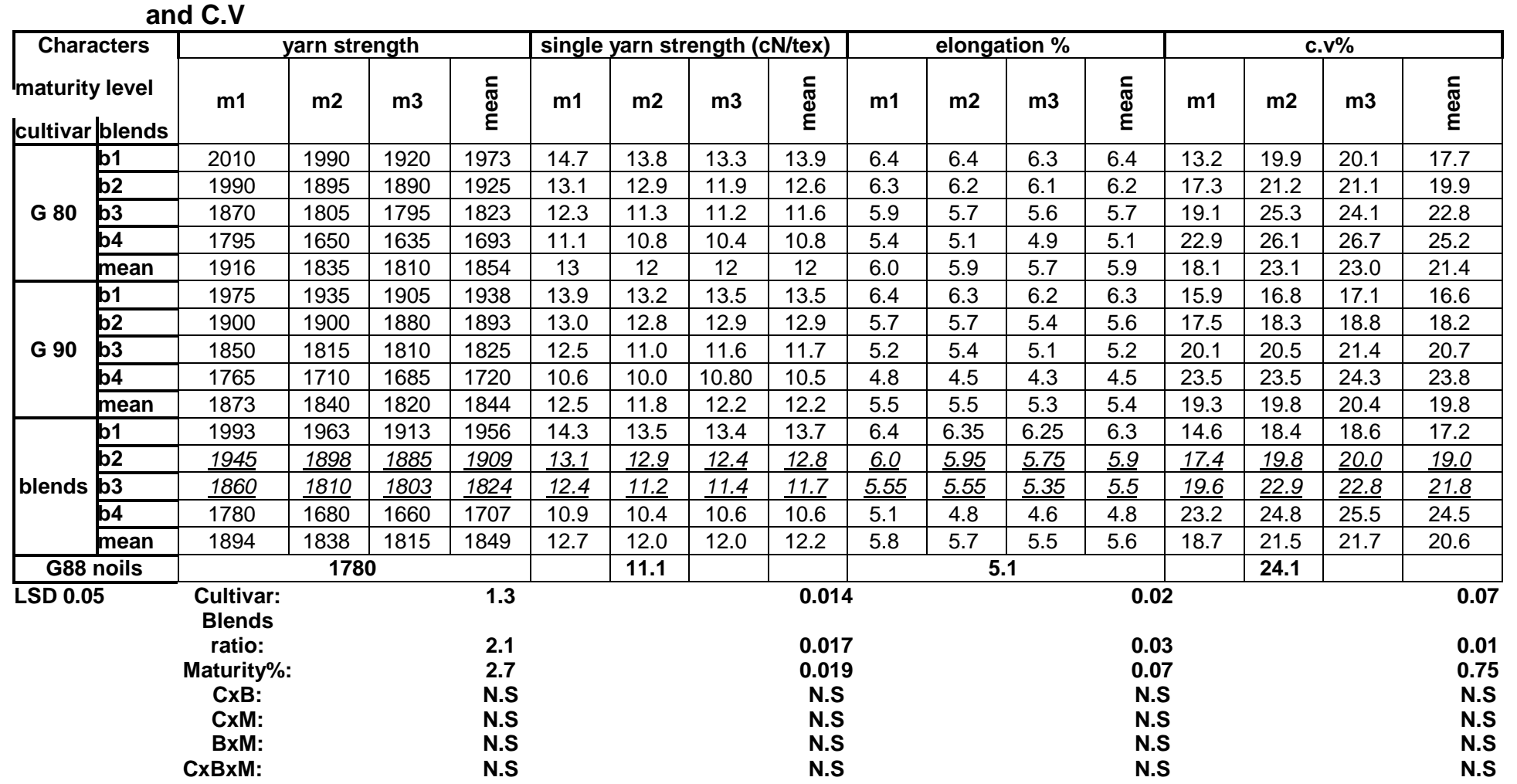


Table (4): Fiber Color measurements as influenced by cotton blend ratios

\begin{tabular}{|c|c|c|c|c|c|c|c|c|c|c|c|c|c|}
\hline \multirow{2}{*}{\multicolumn{2}{|c|}{$\begin{array}{c}\text { Characters } \\
\text { Grades }\end{array}$}} & \multicolumn{4}{|c|}{ Color measurements (K/S) } & \multicolumn{4}{|c|}{$\Delta \mathbf{E}$} & \multicolumn{4}{|c|}{ Rd } \\
\hline & & m1 & m2 & m3 & mean & m1 & m2 & m3 & mean & m1 & m2 & m3 & mean \\
\hline \multirow[t]{5}{*}{ G 80} & b1 & 35.16 & 32.1 & 31.9 & 32.1 & 88.3 & 87.7 & 87.1 & 87.7 & 67.3 & 65.9 & 65.1 & 66.1 \\
\hline & b2 & 31.3 & 31.0 & 30.1 & 30.8 & 88.1 & 88.1 & 87.3 & 87.8 & 65.2 & 65.3 & 65.0 & 65.2 \\
\hline & b3 & 30.4 & 29.7 & 29.0 & 29.7 & 85.2 & 84.3 & 81.0 & 83.5 & 64.7 & 64.5 & 64.2 & 64.5 \\
\hline & b4 & 28.0 & 27.8 & 27.3 & 27.7 & 83.1 & 81.1 & 78.7 & 81.0 & 64.5 & 64.2 & 64.2 & 64.3 \\
\hline & mean & 30.5 & 30.2 & 29.6 & 30.1 & 86.2 & 85.3 & 83.5 & 85.0 & 65.4 & 65.0 & 64.6 & 65.0 \\
\hline \multirow[t]{5}{*}{ G 90} & b1 & 32.7 & 32.3 & 32.0 & 32.3 & 90.5 & 88.6 & 88.0 & 89.0 & 66.7 & 66.5 & 65.3 & 66.2 \\
\hline & b2 & 31.7 & 30.5 & 29.9 & 30.7 & 88.7 & 88.2 & 88.0 & 88.3 & 66.7 & 65.3 & 64.9 & 65.6 \\
\hline & b3 & 29.8 & 28.7 & 28.2 & 28.9 & 85.2 & 84.2 & 82.0 & 83.8 & 65.3 & 64.9 & 64.9 & 65.0 \\
\hline & b4 & 27.6 & 27.5 & 27.0 & 27.4 & 80.3 & 80.1 & 77.6 & 79.3 & 64.5 & 64.3 & 64.3 & 64.4 \\
\hline & mean & 30.5 & 29.8 & 29.3 & 29.8 & 86 & 85.3 & 83.9 & 85.1 & 65.8 & 65.3 & 64.9 & 65.3 \\
\hline \multirow[t]{5}{*}{ blends } & $\mathrm{b} 1$ & 32.5 & 30.1 & 29.7 & 30.7 & 89.4 & 88.2 & 87.6 & 88.4 & 67.0 & 65.4 & 64.8 & 65.7 \\
\hline & b2 & 31.5 & 30.8 & 30.0 & 30.8 & 88.4 & 88.2 & 87.7 & 88.1 & 66.0 & 65.3 & 65.0 & 65.4 \\
\hline & b3 & 30.1 & 29.2 & 28.6 & 29.3 & 85.2 & 84.3 & 81.5 & 83.7 & 65.0 & 64.7 & 64.6 & 64.8 \\
\hline & b4 & 27.8 & 27.7 & 27.2 & 27.5 & 81.7 & 80.6 & 78.2 & 80.2 & 64.5 & 64.3 & 64.3 & 64.3 \\
\hline & mean & 30.5 & 29.4 & 28.9 & 29.6 & 86.2 & 85.3 & 83.7 & 85.1 & 65.6 & 64.9 & 64.6 & 65.0 \\
\hline \multicolumn{2}{|c|}{ G88 noils } & & 28.1 & & & & 66.9 & & & & 28.1 & & \\
\hline \multicolumn{14}{|c|}{ LSD 0.05} \\
\hline \multirow{2}{*}{\multicolumn{3}{|c|}{$\begin{array}{l}\text { Cultivars } \\
\text { Blend ratio }\end{array}$}} & \multirow{2}{*}{\multicolumn{3}{|c|}{$\begin{array}{l}0.023 \\
0.017\end{array}$}} & \multirow{2}{*}{\multicolumn{4}{|c|}{$\begin{array}{l}0.035 \\
0.041\end{array}$}} & & \multicolumn{3}{|c|}{ n..s } \\
\hline & & & & & & & & & & & \multicolumn{3}{|c|}{ n..s } \\
\hline \multicolumn{3}{|c|}{ Maturity ratio } & \multicolumn{3}{|c|}{0.019} & \multicolumn{4}{|c|}{0.047} & & \multicolumn{3}{|c|}{ n..s } \\
\hline \multicolumn{3}{|c|}{ CxB } & \multicolumn{3}{|c|}{0.025} & \multicolumn{4}{|c|}{0.053} & & \multirow{2}{*}{\multicolumn{3}{|c|}{ n..s }} \\
\hline \multicolumn{3}{|l|}{ BxM } & \multicolumn{3}{|c|}{0.045} & \multirow{2}{*}{\multicolumn{4}{|c|}{$\begin{array}{l}0.061 \\
0.089\end{array}$}} & & & & \\
\hline \multicolumn{3}{|l|}{ CXBxM } & \multicolumn{3}{|c|}{0.059} & & & & & & \multicolumn{3}{|c|}{ n..s } \\
\hline
\end{tabular}

